\title{
Lower carbohydrate and higher fat intakes are associated with higher hemoglobin A1c: findings from the UK National Diet and Nutrition Survey 2008-2016
}

\author{
Chaitong Churuangsuk ${ }^{1}$ D $\cdot$ Michael E.J. Lean $^{1}$ (D) Emilie Combet $^{1}$ (D)
}

Received: 20 March 2019 / Accepted: 21 October 2019 / Published online: 4 November 2019

(c) The Author(s) 2019

\begin{abstract}
Purpose Evidence of low-carbohydrate, high-fat diets (LCHF) for type 2 diabetes (T2DM) prevention is scarce. We investigated how carbohydrate intake relates to HbA1c and T2DM prevalence in a nationally representative survey dataset.

Methods We analyzed dietary information (4-day food diaries) from 3234 individuals aged $\geq 16$ years, in eight waves of the UK National Diet and Nutrition Survey (2008-2016). We calculated LCHF scores (0-20, higher score indicating lower \%food energy from carbohydrate, with reciprocal higher contribution from fat) and UK Dietary Reference Value (DRV) scores ( $0-16$, based on UK dietary recommendations). Associations between macronutrients and diet scores and diabetes prevalence were analyzed (in the whole sample) using multivariate logistic regression. Among those without diabetes, analyses between exposures and \%HbA1c (continuous) were analyzed using multivariate linear regression. All analyses were adjusted for age, sex, body mass index, ethnicity, smoking status, total energy intake, socioeconomic status and survey years. Results In the overall study sample, 194 (6.0\%) had diabetes. Mean intake was 48.0\% E for carbohydrates, and 34.9\% E for total fat. Every $5 \% \mathrm{E}$ decrease in carbohydrate, and every $5 \% \mathrm{E}$ increase in fat, was associated with $12 \%$ (95\% CI $0.78-0.99$; $P=0.03)$ and $17 \%(95 \% \mathrm{CI} 1.02-1.33 ; P=0.02)$ higher odds of diabetes, respectively. Each two-point increase in LCHF score is related to $8 \%$ (95\% CI 1.02-1.14; $P=0.006$ ) higher odds of diabetes, while there was no evidence for association between DRV score and diabetes. Among the participants without diagnosed diabetes $(n=3130)$, every $5 \% \mathrm{E}$ decrease in carbohydrate was associated with higher \% HbAlc by $+0.016 \%$ (95\% CI $0.004-0.029 ; P=0.012)$, whereas every $5 \% \mathrm{E}$ increase in fat was associated with higher \%HbAlc by $+0.029 \%$ (95\% CI $0.015-0.043 ; P<0.001)$. Each two-point increase in LCHF score is related to higher $\% \mathrm{HbA} 1 \mathrm{c}$ by $+0.010 \%(0.1 \mathrm{mmol} / \mathrm{mol})$, while each two-point increase in the DRV score is related to lower \% HbA1c by $-0.023 \%(0.23 \mathrm{mmol} / \mathrm{mol})$.

Conclusions Lower carbohydrate and higher fat intakes were associated with higher HbA1c and greater odds of having diabetes. These data do not support low(er) carbohydrate diets for diabetes prevention.
\end{abstract}

Keywords Reduced carbohydrate diet · Carbohydrate-restricted diet $\cdot$ High-fat diet · Dietary recommendation · Glycated hemoglobin · Type 2 diabetes

$\begin{array}{ll}\text { Abbreviations } \\ \text { T2DM } & \text { Type 2 diabetes } \\ \text { LCHF } & \text { Low-carbohydrate, high-fat diet } \\ \text { NDNS } & \text { National diet and nutrition survey } \\ \text { DRV } & \text { Dietary reference value } \\ \text { NMES } & \text { Non-milk extrinsic sugar } \\ \text { NSP } & \text { Non-starch polysaccharide } \\ \text { BMI } & \text { Body mass index } \\ \text { NS-SEC } & \begin{array}{l}\text { National statistics socio-economic } \\ \text { classification }\end{array}\end{array}$

Electronic supplementary material The online version of this article (https://doi.org/10.1007/s00394-019-02122-1) contains supplementary material, which is available to authorized users.

Emilie Combet

Emilie.combetaspray@glasgow.ac.uk

1 Human Nutrition, School of Medicine, Dentistry and Nursing, College of Medical, Veterinary and Life Sciences, University of Glasgow, New Lister Building, Glasgow Royal Infirmary, Room 2.22, Level 2, 10-16 Alexandra Parade, Glasgow G31 2ER, UK 


\section{Introduction}

Diabetes prevalence is predicted to rise from 425 million people in 2017 to 629 million people by 2045 [1]. It is clear that body fat accumulation is the dominant factor behind development of type 2 diabetes mellitus (T2DM), and consistent evidence shows that reversing that process by weight loss is the key mechanism for prevention, as well as for remission of established T2DM [2]. Several large diabetes prevention trials have shown modest weight loss to be effective, principally by lowering fat intake $(<30 \% \mathrm{E})$ along with lifestyle modification [3-6].

It has been hypothesized that lower postprandial glucose excursion on a low-carbohydrate, high-fat (LCHF) diet may lead to a better glucose control [7, 8]. LCHF diets have been promoted as a possible strategy for the management and prevention of T2DM, but there is no consensus on the best macronutrient composition [9]. LCHF diets can certainly lead to weight loss and reduce $\mathrm{HbAlc}$, but there is no clear evidence of LCHF diet superiority over other dietary approaches, with most of meta-analyses of low to moderate methodological quality [10-13]. Furthermore, there are indications that carbohydrate-restricted diets may not provide the full complement of micronutrients leading to potential insufficiencies in vitamins and minerals [14].

Longitudinal cohort studies have not shown conclusive associations between LCHF diets and long-term risk of T2DM [15-17]. No LCHF diet trial (whether or not as part of a wider lifestyle modification) has yet been conducted aiming to prevent incident T2DM [18].

The present study was conducted using the National Diet and Nutrition Survey (NDNS), the largest UK database of a continuous, cross-sectional survey for nutrition and health, using prospective dietary records and providing information on biomarkers. It investigated the relationships of reported dietary carbohydrate, fat, saturated fat, LCHF dietary patterns and adherence to dietary recommendations with $\mathrm{HbAl}$ c concentration (as a marker of diabetes and heart disease risks) and with risk of T2DM.

\section{Subjects and methods}

\section{Study design}

The present study is a secondary analysis of publicly available data from the NDNS rolling program 2008-2016. This is a continuous cross-sectional survey providing high quality, nationally representative data on food consumption, lifestyle, and health information including laboratory data of micronutrients and metabolic risk factors. Representative samples of individuals aged 1.5 year and over were studied each year, providing a total of 12,097 respondents. Ethical approval for the NDNS was granted by appropriate Local Research Ethics Committees and the data can be accessed online through the UK Data Service [19].

\section{Population}

Participants were randomly selected from a sample of private households in the UK Postcode Address File. They were included in the present analysis if they were aged $\geq 16$ years (the minimum age that could consent to the blood test), had complete information on dietary data, health habits, anthropometric data, blood analysis and had plausible reported energy intake (as an average of 3-4 food diary days) defined as $>600 \mathrm{kcal} \&<4200 \mathrm{kcal}$ per day for men and $>500 \mathrm{kcal} \&<3600 \mathrm{kcal}$ per day for women [20]. The participant inclusion flow chart is shown in Fig. 1.

\section{Dietary measure and exposure variables}

The NDNS dietary assessment is a prospective 4-day food diary (covering 2 weekdays and 2 weekend days) with instructions on how to estimate portion size. This 4-day food diary has been validated against four non-consecutive days interviewer-administered 24-hour recalls, NDNS appendix A [21]. In the present study, exposures were the percentages of energy intake from carbohydrate, protein, fat including saturated fat, and the adherences to LCHF dietary pattern and UK dietary recommendations-all as continuous variables.

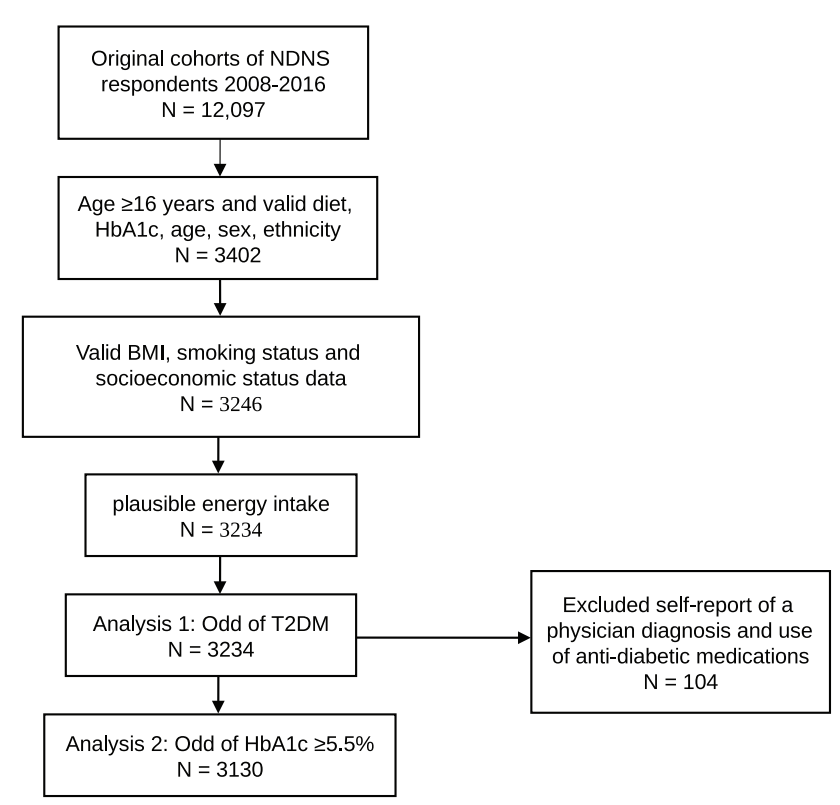

Fig. 1 Flowchart of participant inclusion. NDNS national diet and nutrition survey, $B M I$ body mass index, T2DM type 2 diabetes mellitus 
Adherence to an LCHF dietary pattern was defined by an 'LCHF score' calculated using the percentage of food energy derived from carbohydrate and fat, based on the approach of Sjogren et al. and de Koning et al. [15, 22]. Both carbohydrate and fat intakes were divided into 11 equal groups, assigned a score of 0 to 10 . The lowest carbohydrate intake group $(\leq 39.5 \% \mathrm{E})$ was assigned a score of 10 , and the highest carbohydrate intake group was assigned a score of 0 . Scoring for fat intake was reversed, the lowest fat intake group was assigned a score of 0 , and the highest fat intake group $(>42.9 \% \mathrm{E})$ was assigned a score of 10 . The overall LCHF score ranged from 0 to 20 , with a higher score

Table 1 Population characteristics

\begin{tabular}{|c|c|c|c|c|c|c|c|}
\hline & \multirow{2}{*}{$\begin{array}{l}\text { All } \\
n=3234\end{array}$} & \multirow{2}{*}{$\begin{array}{l}\text { Diagnosis of diabetes } \\
n=104\end{array}$} & \multicolumn{5}{|c|}{ Not known to have diabetes $(n=3130)$} \\
\hline & & & $\begin{array}{l}\mathrm{HbA} 1 \mathrm{c}<5.5 \% \\
n=1613\end{array}$ & $\begin{array}{l}\text { HbA } 1 c \geq 5.5 \% \\
n=1427\end{array}$ & $\begin{array}{l}\mathrm{HbA} 1 \mathrm{c} \geq 6.5 \% \\
n=90\end{array}$ & $\begin{array}{l}\text { Not dieting } \\
n=2741\end{array}$ & $\begin{array}{l}\text { Dieting } \\
n=389\end{array}$ \\
\hline$\% \mathrm{HbA} 1 \mathrm{c}$ & $5.6 \pm 0.7$ & $7.7 \pm 1.7$ & $5.2 \pm 0.2$ & $5.8 \pm 0.2$ & $7.4 \pm 1.2$ & $5.5 \pm 0.5$ & $5.5 \pm 0.5$ \\
\hline $\mathrm{HbA} 1 \mathrm{c} \geq 5.5 \%(\%)$ & - & - & - & - & - & $1323(48.3)$ & $194(49.9)$ \\
\hline Dieting (\%) & $441(12.7)$ & $22(21.2)$ & $195(12.1)$ & $180(12.6)$ & $14(15.6)$ & - & - \\
\hline Age, years & $46.3 \pm 18.5$ & $58.6 \pm 14.4$ & $37.9 \pm 16.1$ & $53.9 \pm 17.1$ & $62.8 \pm 15.2$ & $45.9 \pm 18.9$ & $45.9 \pm 15.5$ \\
\hline Sex: male $(\%)$ & $1379(42.6)$ & $67(64.4)$ & $663(41.1)$ & $607(42.5)$ & $42(46.7)$ & $1207(44.0)$ & $105(27.0)$ \\
\hline BMI $\left(\mathrm{kg} / \mathrm{m}^{2}\right)$ & $27.1 \pm 5.4$ & $31.8 \pm 6.4$ & $25.9 \pm 5.0$ & $27.9 \pm 5.3$ & $31.6 \pm 5.7$ & $26.5 \pm 5.1$ & $30.5 \pm 5.2$ \\
\hline Ethnicity: White (\%) & $3025(93.5)$ & $92(88.5)$ & $1521(94.3)$ & $1330(93.2)$ & $82(91.1)$ & $2568(93.7)$ & $365(93.8)$ \\
\hline \multicolumn{8}{|l|}{ Smoking (\%) } \\
\hline Current smoker & $664(20.5)$ & $12(11.5)$ & $314(19.5)$ & $323(22.6)$ & $15(16.7)$ & $603(22.0)$ & $49(12.6)$ \\
\hline Ex-smoker & $718(22.2)$ & 37 (35.6) & $304(18.8)$ & $345(24.2)$ & $32(35.6)$ & $574(20.9)$ & $107(27.5)$ \\
\hline Never & $1852(57.3)$ & $55(52.9)$ & 995 (61.7) & $759(53.2)$ & $43(47.8)$ & $1564(57.1)$ & $233(59.9)$ \\
\hline \multicolumn{8}{|l|}{$\begin{array}{l}\text { Socioeconomic status } \\
(\%)\end{array}$} \\
\hline Higher professional & $497(15.4)$ & $17(16.3)$ & $283(17.5)$ & $188(13.2)$ & $9(10)$ & $433(15.8)$ & $47(12.1)$ \\
\hline Lower professional & $866(26.8)$ & $20(19.2)$ & 447 (27.7) & $387(27.1)$ & $12(13.3)$ & $740(27.0)$ & $106(27.2)$ \\
\hline $\begin{array}{l}\text { Intermediate occupa- } \\
\text { tions }\end{array}$ & $316(9.8)$ & $6(5.8)$ & $168(10.4)$ & $133(9.3)$ & $9(10)$ & $265(9.7)$ & 45 (11.6) \\
\hline Small employers & $339(10.5)$ & $13(12.5)$ & $143(8.9)$ & $170(11.9)$ & $13(14.4)$ & $280(10.2)$ & $46(11.8)$ \\
\hline Technical occupations & $312(9.6)$ & $15(14.4)$ & $155(9.6)$ & $133(9.3)$ & $9(10)$ & $254(9.3)$ & $43(11.1)$ \\
\hline $\begin{array}{l}\text { Semi-routine occupa- } \\
\text { tions }\end{array}$ & $429(13.3)$ & $15(14.4)$ & $205(12.7)$ & $196(13.7)$ & $13(14.4)$ & $363(13.2)$ & $51(13.1)$ \\
\hline Routine occupations & $357(11.0)$ & $18(17.3)$ & $141(8.7)$ & $180(12.6)$ & $18(20)$ & $298(10.9)$ & $41(10.5)$ \\
\hline Never worked/Other & $118(3.6)$ & - & $71(4.4)$ & $40(2.8)$ & $7(7.8)$ & $108(3.9)$ & $10(2.6)$ \\
\hline Total Energy (kcal) & $1815.4 \pm 551.4$ & $1770.7 \pm 575.2$ & $1844.9 \pm 556.5$ & $1795.0 \pm 543.1$ & $1660.7 \pm 523.9$ & $1845.4 \pm 555$ & $1612.9 \pm 472$ \\
\hline Carbohydrate (g/day) & $221.4 \pm 71.0$ & $210.7 \pm 69.6$ & $226.5 \pm 73.1$ & $217.7 \pm 68.4$ & $202.0 \pm 66.9$ & $225.3 \pm 71.6$ & $197.2 \pm 62.1$ \\
\hline Carbohydrate (\%E) & $48.0 \pm 6.6$ & $46.6 \pm 7.0$ & $48.6 \pm 6.6$ & $47.6 \pm 6.5$ & $47.1 \pm 6.7$ & $48.1 \pm 6.5$ & $47.8 \pm 7.1$ \\
\hline Fat (g/day) & $68.2 \pm 25.8$ & $68.6 \pm 27.4$ & $68.2 \pm 25.7$ & $68.3 \pm 25.8$ & $64.0 \pm 24.4$ & $69.5 \pm 25.8$ & $58.4 \pm 22.8$ \\
\hline Fat $(\% \mathrm{E})$ & $34.9 \pm 6.2$ & $35.5 \pm 6.2$ & $34.5 \pm 6.3$ & $35.3 \pm 6.0$ & $35.4 \pm 6.3$ & $35.1 \pm 6.0$ & $33.4 \pm 7.0$ \\
\hline Saturated fat (g/day) & $25.4 \pm 11.0$ & $25.6 \pm 11.4$ & $25.1 \pm 10.8$ & $25.8 \pm 11.1$ & $24.5 \pm 11.5$ & $26.0 \pm 11.0$ & $21.5 \pm 9.8$ \\
\hline Saturated fat $(\% \mathrm{E})$ & $13.0 \pm 3.3$ & $13.1 \pm 3.4$ & $12.6 \pm 3.3$ & $13.3 \pm 3.4$ & $13.3 \pm 3.6$ & $13.1 \pm 3.3$ & $12.2 \pm 3.5$ \\
\hline Protein (g/day) & $72.6 \pm 22.6$ & $75.2 \pm 24.5$ & $72.7 \pm 23.1$ & $72.5 \pm 22.0$ & $69.0 \pm 21.4$ & $72.6 \pm 22.6$ & $71.5 \pm 22.1$ \\
\hline Protein (\%E) & $17.1 \pm 3.8$ & $18.0 \pm 4.3$ & $16.9 \pm 3.9$ & $17.2 \pm 3.6$ & $17.5 \pm 3.9$ & $16.8 \pm 3.6$ & $18.8 \pm 4.2$ \\
\hline $\begin{array}{l}\text { Non-starch polysaccha- } \\
\text { ride (g/day) }\end{array}$ & $13.7 \pm 5.0$ & $14.1 \pm 5.5$ & $13.7 \pm 5.0$ & $13.7 \pm 4.9$ & $13.1 \pm 5.2$ & $13.7 \pm 5.0$ & $13.6 \pm 4.8$ \\
\hline $\begin{array}{l}\text { Fruit and Vegetables } \\
\text { (g/day) }\end{array}$ & $277.4 \pm 172.1$ & $273.5 \pm 181.9$ & $271.8 \pm 172.9$ & $283.5 \pm 169.1$ & $283.7 \pm 192.1$ & $271.9 \pm 166.2$ & $316.6 \pm 203.3$ \\
\hline $\begin{array}{l}\text { LCHF score, median } \\
\text { (IQR) }\end{array}$ & $10(5,15)$ & $12(6,17)$ & $10(4,15)$ & $10(6,15)$ & $11(6,16)$ & $10(5,15)$ & $9(4,15)$ \\
\hline $\begin{array}{l}\text { DRV score, median } \\
\text { (IQR) }\end{array}$ & $6(4,8)$ & $5(4,8)$ & $5(4,8)$ & $6(4,8)$ & $5(4,9)$ & $5(4,8)$ & $6(4,9)$ \\
\hline
\end{tabular}

Data are mean \pm SD unless otherwise indicated 
indicating higher adherence to LCHF diets, lower intake of carbohydrate and higher intake of fat (Online Resource Table 1).

Adherence to UK dietary recommendations (Dietary Reference Value, 'DRV score') was calculated according to the method by Eriksen and colleagues, derived from 8 nutrients and foods: carbohydrate \%food energy, fat \%food energy, saturated fat \%food energy, sugar (as non-milk extrinsic sugar, NMES) \% food energy, fruit and vegetables in grams of intake, fish in grams of intake, sodium in mg of intake, and fiber (as non-starch polysaccharide, NSP) in grams of intake [23]. DRV score ranged from 0 to 16, with higher DRV scores indicative of a higher adherence to UK dietary recommendations (Online Resource Table 2).

\section{Covariates}

The following variables were determined a priori as potentially affecting HbA1c and/or diet composition: age, sex, ethnicity (White, Asian, Black, Mixed, and other), body mass index (BMI), smoking status (current smoker, exsmoker, never smoked), energy intake, socioeconomic status defined by the National Statistics Socio-Economic Classification (NS-SEC), and survey year. All covariate information including whether currently on a weight-loss diet was gathered during face-to-face interviews conducted by the NDNS researchers. Body weight was measured by a scale and body height was measured by a stadiometer during the interview. BMI is calculated by body weight $(\mathrm{kg})$ divided by a square of height $(\mathrm{m})$.

\section{Outcome variables}

Two primary outcomes were defined. The primary outcome 1 , having diabetes, was analyzed using the whole dataset.
Diabetes status was either diagnosed diabetes (based on selfreport of a physician diagnosis and/or use of anti-diabetic medications) or $\mathrm{HbA} 1 \mathrm{c} \geq 6.5 \%$ in those who had never been diagnosed before. The NDNS dataset does not break down type 1 and type 2 diabetes, nor insulin use. Therefore, we conducted a sensitivity analysis by excluding possible T1DM from the dataset (further details in the statistical analysis section below).

The primary outcome 2 was HbA1c concentration among those without diabetes. Therefore, participants with diagnosed diabetes (based on self-report of a physician diagnosis and/or use of anti-diabetic medications) were excluded to reduce bias from reverse causality, as diagnosis and treatment would be likely to affect both diets and HbA1c (e.g., those with diagnosed diabetes might have reduced carbohydrate intake). HbAlc was analyzed as a continuous variable to investigate how carbohydrates and diets relate to $\mathrm{HbA} 1 \mathrm{c}$ concentration. We also investigated how dietary carbohydrate relates to cardiovascular disease risk, by categorizing HbA1c into a binary outcome, using a cut point of $\geq 5.5 \%$ as a clinically meaningful threshold $(2.5-7.8 \%$ per 100 person-year increase in T2DM annual incident rate, $21-61 \%$ increase in cardiovascular death; compared to $\mathrm{HbA} 1 \mathrm{c}<5.5 \%$ ) [24, 25].

\section{Statistical analysis}

Only participants who had complete data for all variables were included in the analysis. Men and women were combined in the analysis to increase the power, as there was no difference in diet recommendation between sexes. Data are presented as percentage of total, means and standard deviations (unless otherwise stated).

Primary outcome 1: associations between T2DM status and dietary exposures (macronutrients as percentage of
Table 2 Associations between $\% \mathrm{HbA} 1 \mathrm{c}$ concentration and macronutrients and dietary adherence scores in subjects without diagnosed diabetes $(n=3130)$

\begin{tabular}{lrlcrr}
\hline Predictors & $\beta^{\mathrm{a}}$ & SE & Lower 95\% CI & Upper 95\% CI & $P$ value \\
\hline Macronutrients $^{\mathrm{b}}$ & & & & & \\
Carbohydrate & -0.016 & 0.007 & -0.029 & -0.004 & 0.012 \\
Fat & 0.029 & 0.007 & 0.015 & 0.043 & $<0.001$ \\
Saturated fat & 0.051 & 0.013 & 0.025 & 0.078 & $<0.001$ \\
Protein & -0.027 & 0.012 & -0.050 & -0.004 & 0.024 \\
Adherence score & & & & 0.016 & 0.001 \\
LCHF score & 0.010 & 0.003 & 0.004 & -0.012 & $<0.001$ \\
DRV score & -0.023 & 0.006 & -0.035 &
\end{tabular}

$L C H F$ low carbohydrate high fat, $D R V$ dietary reference values, $C I$ confidence interval, $S E$ standard error

${ }^{a}$ Multivariate linear regression model with regression coefficients $(\beta)$ in $\% \mathrm{HbA} 1 \mathrm{c}$ change for $5 \%$ food energy increment and 2-point diet score increment adjusted for age, sex, BMI, ethnicity, smoking status, socioeconomic status, survey year, and energy intake

${ }^{\mathrm{b}} \mathrm{Per} 5 \%$ food energy increment

${ }^{\mathrm{c}}$ Per 2-point score increment 
food energy and diet scores) were analyzed using multivariate logistic regression with adjustment for covariates. Analyses were conducted in the whole dataset. Because the dataset does not allow T1DM and T2DM to be identified separately, we carried out two sensitivity analyses. There is a greater likelihood of T1DM among people with diabetes at younger ages. We firstly conducted a sensitivity analysis by excluding all participants age under 30 years.

We carried out another sensitivity analysis by randomly excluding $10 \%$ of participants with diabetes, based on the overall T1DM prevalence of approximately $10 \%$ of total diabetes prevalence, weighted by age groups [26]. In the main NDNS dataset, there are 104 participants with diabetes, which means that about 10 may have T1DM. We, therefore, did not just randomly exclude $10 \%$ of participants with diabetes. Instead, this analysis was based on 1000 separate analyses, with random sampling and exclusions of 10 different participants with diabetes, weighted for age (online Resource Table 3 shows the prevalence of T1DM in all patients with diabetes, stratified by age groups). The recent National Diabetes Audit Report showed that T1DM presents in all age groups with higher proportion in younger age $(67.4 \%$ in those aged 20-29 years with diabetes) compared to older age (3.4\% in those aged 60-69 years with diabetes). We selected the $10 \%$ for exclusion using the number reflecting the prevalence of T1DM in each age group [26]. This sensitivity analysis aimed to explore how much estimates (Odds Ratio) differed when excluding possible T1DM patients from the analyses.

We also conducted a third sensitivity analysis by excluding individuals with known (diagnosed) diabetes $(n=104$ out of 194) to explore the associations between diets and unknown T2DM prevalence $(n=90)$. Finally, a fourth sensitivity analysis was conducted by excluding individuals with T2DM being on a weight-loss diet ( $n=36$ out of 194) to explore how much odds ratio differed when excluding the possible effect of weight loss.

Primary outcome 2: in participants without diagnosed diabetes, multiple linear regression was conducted to analyze relationships between macronutrients, diet scores and $\mathrm{HbA} 1 \mathrm{c}$ concentration, and multivariate logistic regression was used to test associations between diets and having $\mathrm{HbA} 1 \mathrm{c} \geq 5.5 \%$. All analyses were adjusted for covariates.

Table 3 Sensitivity analyses in subjects without diagnosed diabetes aged $\geq 18$ years $(n=2865)$, and not being on a weight-loss diet $(n=2741)$ showing associations between \%HbA1c and macronutrients and diet scores

\begin{tabular}{|c|c|c|c|c|c|c|c|c|}
\hline \multirow[b]{2}{*}{ Predictors } & \multicolumn{3}{|c|}{$\mathrm{HbA} 1 \mathrm{c} \geq 5.5 \%$} & \multicolumn{5}{|c|}{$\% \mathrm{HbA} 1 \mathrm{c}$ concentration } \\
\hline & Odds Ratio $^{\mathrm{a}}$ & $95 \% \mathrm{CI}$ & $P$ value & $\beta^{\mathrm{b}}$ & SE & Lower $95 \%$ CI & Upper $95 \%$ CI & $P$ value \\
\hline \multicolumn{9}{|c|}{ Age $\geq 18$ years $(n=2865)$} \\
\hline \multicolumn{9}{|c|}{ Macronutrients $^{c}$} \\
\hline Carbohydrate & 0.94 & $0.88-1.00$ & 0.046 & -0.015 & 0.007 & -0.028 & -0.002 & 0.020 \\
\hline Fat & 1.14 & $1.06-1.22$ & $<0.001$ & 0.027 & 0.007 & 0.013 & 0.041 & $<0.001$ \\
\hline Saturated fat & 1.26 & $1.10-1.44$ & $<0.001$ & 0.044 & 0.013 & 0.018 & 0.070 & $<0.001$ \\
\hline Protein & 0.88 & $0.78-0.99$ & 0.034 & -0.025 & 0.012 & -0.048 & -0.001 & 0.039 \\
\hline \multicolumn{9}{|l|}{ Adherence score ${ }^{\mathrm{d}}$} \\
\hline LCHF score & 1.04 & $1.01-1.07$ & 0.014 & 0.009 & 0.003 & 0.004 & 0.015 & 0.001 \\
\hline DRV score & 0.91 & $0.86-0.97$ & 0.002 & -0.020 & 0.006 & -0.031 & -0.008 & $<0.001$ \\
\hline \multicolumn{9}{|c|}{ No weight-loss diet $(n=2741)$} \\
\hline \multicolumn{9}{|l|}{ Macronutrients $^{\mathrm{c}}$} \\
\hline Carbohydrate & 0.94 & $0.88-1.01$ & 0.085 & -0.014 & 0.007 & -0.028 & 0.000 & 0.051 \\
\hline Fat & 1.11 & $1.03-1.20$ & 0.005 & 0.026 & 0.008 & 0.011 & 0.042 & 0.001 \\
\hline Saturated fat & 1.24 & $1.08-1.42$ & 0.003 & 0.050 & 0.014 & 0.022 & 0.079 & 0.001 \\
\hline Protein & 0.91 & $0.80-1.03$ & 0.145 & -0.026 & 0.013 & -0.052 & 0.000 & 0.048 \\
\hline \multicolumn{9}{|c|}{ Adherence score ${ }^{\mathrm{d}}$} \\
\hline LCHF score & 1.03 & $1.00-1.06$ & 0.046 & 0.009 & 0.003 & 0.003 & 0.015 & 0.004 \\
\hline DRV score & 0.91 & $0.85-0.96$ & 0.001 & -0.024 & 0.006 & -0.036 & -0.011 & $<0.001$ \\
\hline
\end{tabular}

$L C H F$ low carbohydrate high fat, $D R V$ dietary reference values, $C I$ confidence interval, $S E$ standard error

${ }^{a}$ Multivariate logistic regression adjusted for age, sex, BMI, ethnicity, smoking status, socioeconomic status, survey years, total energy intake

${ }^{\mathrm{b}}$ Multivariate linear regression adjusted for age, sex, BMI, ethnicity, smoking status, socioeconomic status, survey years, total energy intake

${ }^{c}$ Per $5 \%$ food energy increment

${ }^{\mathrm{d}}$ Per 2-point score increment 
Sensitivity analysis was carried out by repeated analysis in (i) people with non-diagnosed diabetes who reported not being on a weight-loss diet; (ii) people with non-diagnosed diabetes aged $\geq 18$ years old; and (iii) in subgroup analysis of people with $\mathrm{BMI}<25 \mathrm{~kg} / \mathrm{m}^{2}$ and $\mathrm{BMI} \geq 25 \mathrm{~kg} / \mathrm{m}^{2}$ (with versus without overweight $\&$ obesity).

All statistical tests were two sided with an alpha of 0.05 . $\mathrm{R}$ version 3.5.1 was used with package 'epical', 'rms' and 'ggplot2' for statistical analysis.

\section{Results}

Table 1 shows population characteristics. Between 2008 and 2016, a total of 3234 participants (mean age $46.3 \pm 18.5$ years, $42.6 \%$ men) had complete data and were included in the analysis. Of these, 104 participants (3.2\%) had a known diagnosis of diabetes. Among those without a diabetes diagnosis $(n=3130)$, mean HbAlc was $5.5 \pm 0.5 \%$, $n=90(2.8 \%)$ had HbA1c $\geq 6.5 \%, n=365$ (11.7\%) had HbAlc $\geq 6.0 \%$, and $n=1517$ (48.5\%) had an HbAlc $\geq 5.5 \%$. Participants with either diabetes or $\mathrm{HbA} 1 \mathrm{c} \geq 5.5 \%$ were older ( $59 \pm 14$ and $54 \pm 17$ years, respectively) and had a higher BMI ( $32 \pm 6$ and $28 \pm 5 \mathrm{~kg} / \mathrm{m}^{2}$, respectively) than those with lower HbA1c (age $38 \pm 16$ years, BMI $26 \pm 5 \mathrm{~kg}$ /

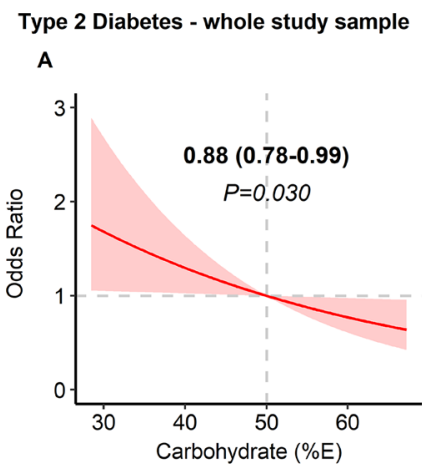

B

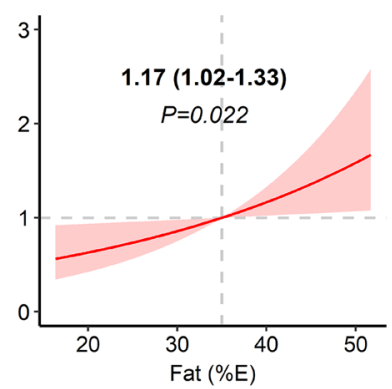

HbA1c $\geq 5.5 \%$ - subjects without Type 2 Diabetes

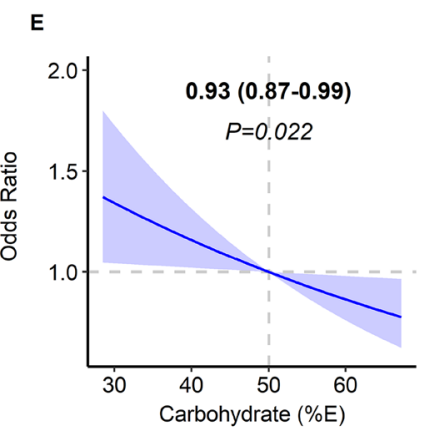

F

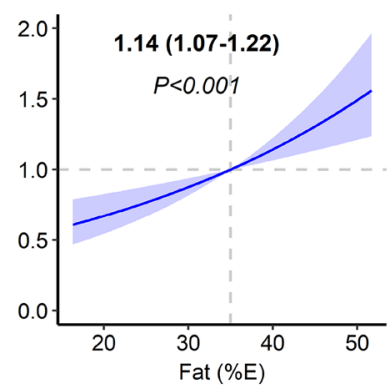

Fig. 2 Associations between macronutrients and odds of diabetes (ad) and elevated $\mathrm{HbA} 1 \mathrm{c} \geq 5.5 \%$ (e-f). Values are odds ratio with $95 \%$ confidence interval calculated from multiple variable logistic regression adjusted for age, sex, body mass index, ethnicity, smoking status, $\left.\mathrm{m}^{2}\right)$. Most participants were white (93.5\%) and non-smokers $(57.3 \%)$, and $12 \%$ were following self-reported weight-loss diets (Table 1).

Dietary intakes were comparable across groups of diagnosed and non-diagnosed diabetes (Table 1). Mean total energy intake was $1815 \pm 551 \mathrm{kcal}$. Carbohydrate, fat, saturated fat and protein intakes were approximately $48 \%, 35 \%$, $13 \%$ and $17 \%$ food energy across all groups. Non-starch polysaccharides intake was low at $13.7 \pm 5 \mathrm{~g} /$ day (target $18 \mathrm{~g} /$ day, Englyst method). Participants who reported being on a weight-loss diet had higher fruits and vegetables intakes $(317 \pm 203 \mathrm{~g} /$ day $)$ than the overall sample population $(277 \pm 172 \mathrm{~g} /$ day $)$, with no difference in LCHF or DRV scores. The distributions of the LCHF and DRV scores are shown in Online Resource Fig. 1. There was a negative correlation between LCHF and DRV scores (rho $=-0.63$, $P<0.001)$.

\section{Primary outcome 1: odds of Type 2 diabetes- analyses in the whole sample}

Macronutrients: Out of 3234 participants, 194 participants $(6 \%)$ were considered as having diabetes. In multivariate logistic regression models adjusted for covariates, an increase of 5\% food energy from carbohydrate
C

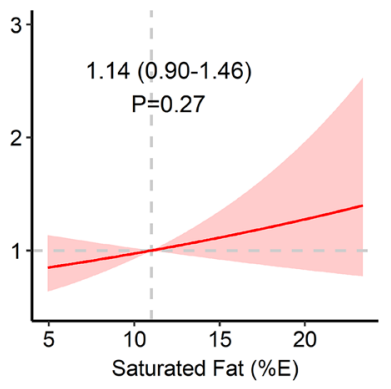

G

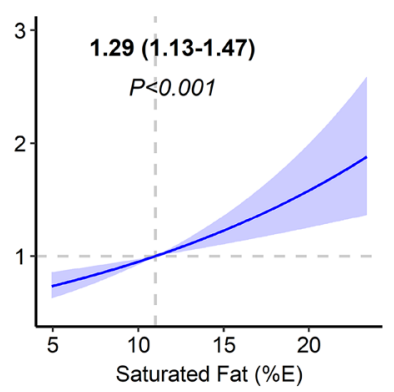

D

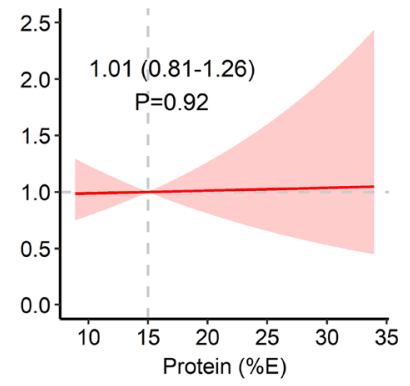

H

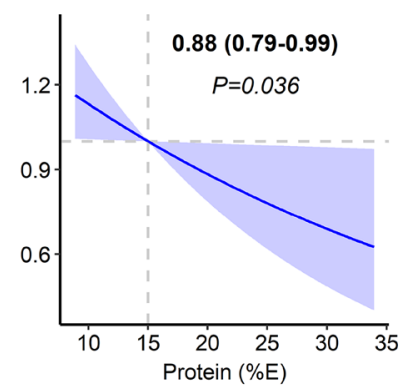

socioeconomic status, survey year and total energy intake. Reference levels for regression analysis: carbohydrate, fat, saturated fat and protein are $50 \%, 35 \%, 11 \%$ and $15 \%$ food energy 
was associated with a $12 \%$ 'lower odd' of having diabetes (95\% CI 0.78-0.99; $P=0.03$ ), while every $5 \%$ food energy increase from fat intake was associated with a $17 \%$ 'higher odd' of diabetes, (95\% CI 1.02-1.33; $P=0.022)$. There was no evidence to support the associations between diabetes and saturated fat and protein intakes (Fig. 2a-d).

Dietary adherence: Every 2-point increase in LCHF score was associated with an $8 \%$ 'higher odds' of diabetes (95\% CI 1.02-1.14; $P=0.006$ ). However, the evidence did not support an association between diabetes and adherence to the UK dietary recommendations (adjusted OR 0.95; 95\% CI $0.85-1.06, P=0.35$ for every 2-point increase in DRV score) (Fig. 3a-b).

Sensitivity analysis: To investigate how estimates differed when we excluded participants with possible T1DM, we conducted two sensitivity analyses (because the dataset does not breakdown T1DM and T2DM): (1) we excluded all participants with diabetes aged under 30; and (2) we conducted 1000 logistic regression analyses after randomly excluding $10 \%$ of population with diabetes $(10 \%$ prevalence of T1DM in total diabetes prevalence) stratified by age groups. The results of the sensitivity analyses remained similar to the main analyses for each macronutrient and dietary adherence score (Online Resource Table 4). We conclude that there was no major effect on our conclusions from the small number (approximately 10) of T1DM patients who may possibly have been included in the sample. Further sensitivity analyses by excluding individuals with known diabetes ( $n=104$ out of 194) and individuals with diabetes being on weight-loss diet ( $n=36$ out of 194) also showed that the direction of associations remained similar and the magnitude of effect size did not change markedly from the main analyses (Online Resource Table 4).

\section{Primary outcome 2: HbA1c concentration-analyses in individuals without diagnosed diabetes}

We conducted analyses in participants without a diabetes diagnosis $(n=3130$ ), to minimize bias from reverse causality as diagnosis and treatment would be likely to affect both diets and $\mathrm{HbA1c}$.
Fig. 3 Associations between diet scores and odds of diabetes $(\mathbf{a}, \mathbf{b})$ and elevated $\mathrm{HbA} 1 \mathrm{c} \geq 5.5 \%(\mathbf{c}, \mathbf{d})$. Values are odds ratio with $95 \%$ confidence interval calculated from multiple variable logistic regression adjusted for age, sex, body mass index, ethnicity, smoking status, socioeconomic status, survey year and total energy intake. Reference level for regression analysis is nine for low-carb, high-fat (LCHF) score and eight for dietary reference value (DRV) score as these scores reflected intakes that met UK recommendations

\section{Type 2 Diabetes - whole study sample}

\section{A}

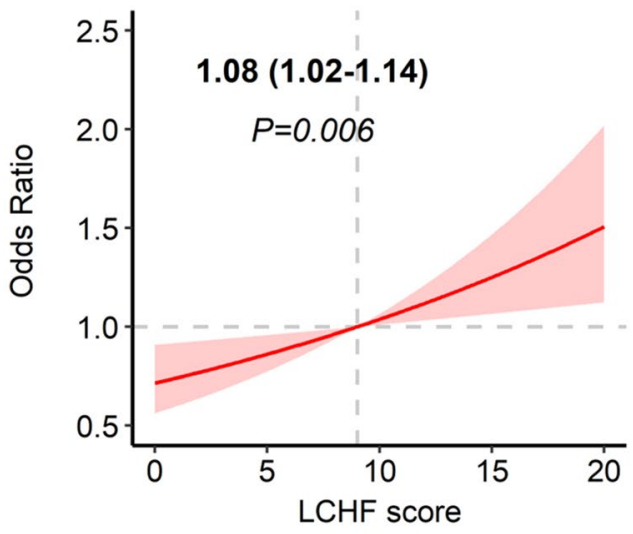

B

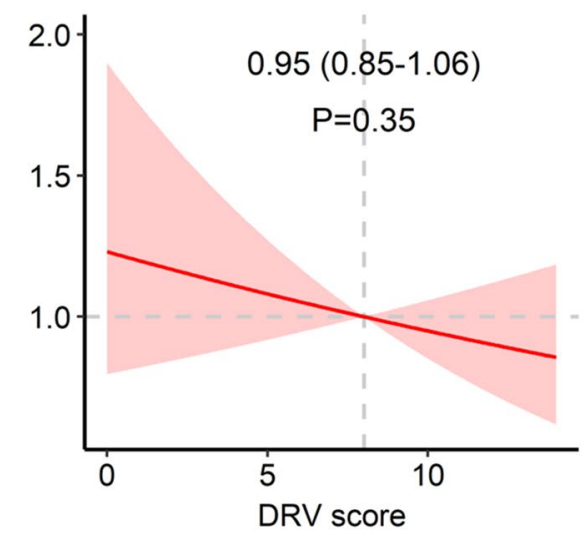

HbA1c $\geq 5.5 \%$ - subjects without Type 2 Diabetes

\section{C}

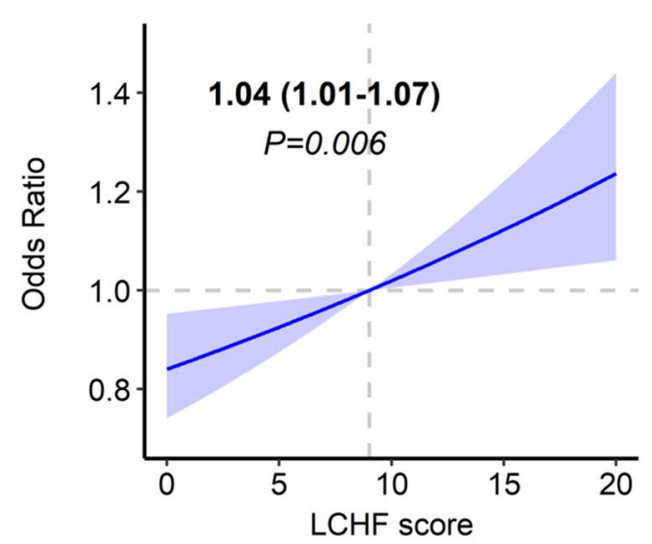

D

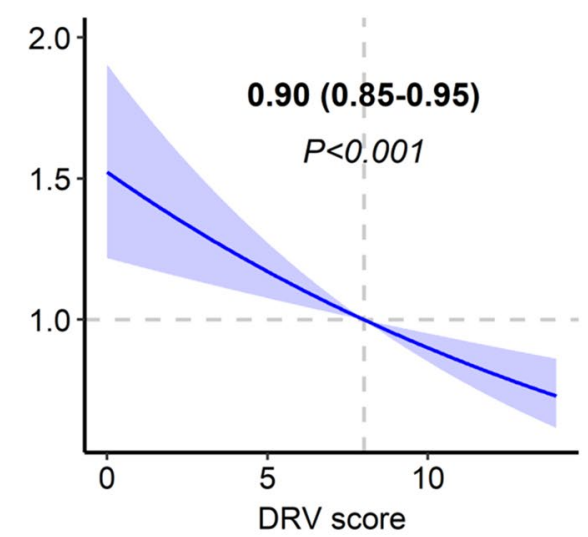


Macronutrients: A higher carbohydrate intake (every extra 5\%food energy) was associated with lower $\% \mathrm{HbA} 1 \mathrm{c}$ ( $-0.016 \%$ or $-0.16 \mathrm{mmol} / \mathrm{mol}$; $95 \%$ CI $-0.029 \%$, $-0.004 \% ; P=0.012)$. A similar association for protein was found, with every extra 5\% food energy from protein associated with lower \%HbA1c $(-0.027 \%$ or $-0.27 \mathrm{mmol} /$ mol; $95 \%$ CI $-0.050 \%,-0.004 \% ; P=0.024)$. In contrast, fat and saturated fat intakes were both associated with higher $\% \mathrm{HbA} 1 \mathrm{c}$, by $+0.029 \%$ (or $+0.29 \mathrm{mmol} / \mathrm{mol} ; 95 \%$ CI $0.015 \%, 0.043 \%$ ) and $+0.051 \%$ (or $+0.51 \mathrm{mmol} / \mathrm{mol}$; $95 \%$ CI $0.025 \%, 0.078 \%$ ), respectively, $P<0.001$ (Table 2 ).

Dietary adherence: A higher LCHF score (per two-point increase) was also associated with higher $\% \mathrm{HbA} 1 \mathrm{c}$ concentration by $+0.010 \%$ (or $0.1 \mathrm{mmol} / \mathrm{mol} ; 95 \%$ CI $0.004 \%$, $0.016 \% ; P=0.001$ ), while higher DRV score (per twopoint increase) was inversely associated with $\% \mathrm{HbA} 1 \mathrm{c}$ by - $0.023 \%$ (or $0.23 \mathrm{mmol} / \mathrm{mol}$; $95 \% \mathrm{CI}-0.035 \%,-0.012 \%$; $P<0.001$ ) (Table 2).

Sensitivity analysis: Similar associations between macronutrients, diet scores and $\mathrm{HbA} 1 \mathrm{c}$ concentration remained in the sensitivity analyses with (1) participants aged $\geq 18$ years old; (2) participants who were not on a weight-loss diet; and (3) in a subgroup of subjects with BMI $\geq 25 \mathrm{~kg} / \mathrm{m}^{2}$ (Table 3 and Online Resource Table 5). However, none of the associations remained significant in individuals with $\mathrm{BMI}<25 \mathrm{~kg} / \mathrm{m}^{2}$, except for saturated fat intake which was associated with higher $\% \mathrm{HbA} 1 \mathrm{c}(+0.04 \%$; $95 \%$ CI $0.01 \%$, $0.07 \% ; P=0.021$ ), per 5\% food energy increment (Online Resource Table 5).

\section{Primary outcome 2: Odds of elevated $\mathrm{HbA1c}(\geq 5.5 \%)$, as a cardiovascular disease risk biomarker-analyses in individuals without diagnosed diabetes}

Macronutrients: Every 5\% extra food energy from carbohydrate and protein were associated with $7 \%(95 \%$ CI $0.87-0.99 ; P=0.022)$ and $12 \%$ (95\% CI $0.79-0.99$; $P=0.036)$ 'lower odds' of elevated $\mathrm{HbA1c}$, respectively. In contrast, every extra $5 \%$ food energy from fat and saturated fat were associated with 'higher odds' of elevated $\mathrm{HbA} 1 \mathrm{c}$, by $14 \%$ (95\% CI $1.07-1.22 ; P<0.001)$ and $29 \%$ (95\% CI 1.13-1.47; $P<0.001$ ), respectively (Fig. 2e-h).

Dietary adherence: associations between diet scores and elevated $\mathrm{HbA} 1 \mathrm{c}$ were found. Every 2-point increase in LCHF score was associated with a $4 \%$ higher odd of having an elevated HbA1c (95\% CI 1.01-1.07; $P=0.006$ ), while every 2-point increase in DRV score was inversely associated with the odd of elevated HbA1c by $10 \%, 95 \%$ CI $0.85-0.95, P<0.001$ (Fig. 3c-d).

Sensitivity analysis: A sensitivity analysis in participants aged $\geq 18$ years old showed associations consistent with the main analysis (Table 3). Similarly, in participants who were not on weight-loss diet, fat and saturated fat intakes remained strongly associated with $11 \%$ (95\% CI 1.03-1.20; $P=0.005)$ and $24 \%$ (95\% CI 1.08-1.42; $P=0.003$ ) higher odds of elevated HbA1c (Table 3). Consistently, LCHF score was associated with higher odds of elevated HbA1c, whereas DRV score was associated with lower odds of elevated HbA1c (Table 3). Further sensitivity analysis in subgroup with overweight/obesity (BMI $\geq 25 \mathrm{~kg} / \mathrm{m}^{2}$ ) showed similar associations between macronutrients, diet scores and odds of elevated $\mathrm{HbA} 1 \mathrm{c}$. In contrast, no evidence was found for these associations in a subgroup with BMI $<25 \mathrm{~kg} / \mathrm{m}^{2}$ (Online Resource Table 5 and Online Resource Fig. 2).

\section{Discussion}

There has been very limited evidence supporting the use of LCHF diets for the prevention of T2DM. To our knowledge, this is the first study investigating whether carbohydrate intake and LCHF dietary pattern relate to HbA1c concentration in a population-based cross-sectional study of nutrition and health. Surprisingly, given the enthusiasm for LCHF diets in the media and from some professional commentators, we found that lower carbohydrate intake was associated with significantly greater odds of T2DM and higher $\mathrm{HbA} 1 \mathrm{c}$ concentration. Higher adherence to conventional dietary recommendations (basing meals on starchy carbohydrates, lower fat and saturated fat contents, eating more fruits and vegetables) was associated with lower $\mathrm{HbA1c}$ concentration.

Few longitudinal cohort studies have evaluated the links between LCHF diets and long-term risk of T2DM, with inconclusive findings [15, 16, 27]. The LCHF dietary pattern was associated with higher T2DM risk in men, women with history of gestational diabetes [15, 27], but another found no association in women without gestational diabetes [16]. A meta-analysis of four prospective studies with follow-up durations 3.6 to 20 years [28] showed no evidence of association between LCHF (highest quantile of LCHF score) and T2DM risk (pooled RR 1.17; 95\% CI 0.90-1.51) but this small study had high heterogeneity $\left(I^{2}=81.5 \%, P<0.001\right)$. The authors did a subgroup analysis in those cohort studies with adjustment for total energy intake ( $n=3$ of 4$)$ and found improvement in heterogeneity (pooled RR 1.32; 95\% CI $\left.1.05-1.75 ; I^{2}=0 \%\right)$ [28]. All included studies $(n=4)$ were assessed as Newcastle-Ottawa Scale $\geq 5$ for methodological quality, but a subgroup analysis by study quality (score $>7$ and $\leq 7$ ) revealed an association only in lower-quality studies (score $\leq 7 ; n=2 / 4$; pooled RR 1.31; 95\% CI 1.15-1.50; $I^{2}=0 \%$ ), with no association in two higher quality studies (score > 7; pooled RR 1.09; 95\% CI: $0.73-1.63 ; I^{2}=86 \%$ ) [28]. The evidence on this topic is clearly scarce and varies in quality, and dietary assessment quality is a limiting factor. All prospective studies used food frequency questionnaires 
for dietary assessment, which are less reliable than the 4-day food diary used in the UK NDNS survey. While cross sectional in nature, our study and indings link LCHF diets to both T2DM and HbA1c level, and therefore add to the findings of previous cohort studies.

A beneficial relationship between adherence to dietary recommendations and lower $\mathrm{HbA} 1 \mathrm{c}$ and $\mathrm{T} 2 \mathrm{DM}$ risk is reassuring, and in keeping with previous literature. Another recent UK cross-sectional study showed similarly that adherence to UK dietary guidelines was associated with lower $\mathrm{HbA} 1 \mathrm{c}$ and T2DM risk [23]. Also, findings from prospective studies showed that adherence to dietary guidelines, increased fruits and vegetables and whole grain intakes were associated with 7-30\% lower risk of T2DM [29-32]. Moreover, a secondary analysis of the Women's Health Initiative Dietary Modification Trial showed that low-fat diet, with increased grains, fruits and vegetables, reduced the rate of conversion from normoglycemia to impaired fasting glucose by $25 \%$ after 8 -year intervention [4]. Notably, participants in this trial increased carbohydrate intake by $~ 8 \%$ of energy, with a corresponding reciprocal decrease in fat intake of $\sim 8 \%$. This also supports the assertion that greater carbohydrate intake, particularly from grains and fruits, could delay progression to T2DM [4].

Other mechanisms (e.g., oxidative stress, peripheral insulin resistance), aside from carbohydrates intake and postprandial glycemia, may contribute to elevation of $\mathrm{HbA1c}$ and might explain the association with lower carbohydrate diets. Avoiding carbohydrate foods like whole grains, fruits and some starchy vegetables inevitably lowers micronutrients and bioactive compounds, fiber, and some minerals (e.g., magnesium) [14]. Lower fruits and associated nutrients and bioactives, alongside higher fat intake, could impact on oxidative stress [33-37]. High oxidative stress consequently enhances protein glycation, including the formation of fructosamine and HbAlc. Vlassopoulos et al. modelled that under normal glucose concentration, higher oxidative stress increases fructosamine production by $35 \%$, compared to non-oxidative state [38].

Oxidative stress, as well low magnesium status and high fatty acids concentration (from high-fat intake), also raises insulin resistance through an alteration in the insulin receptor signaling pathway $[39,40]$. A recent well-controlled crossover isocaloric feeding study in adults with overweight/ obesity reported a decline in insulin sensitivity, reduction in glucose disposal rate by $-0.37 \pm 0.15 \mathrm{mmol} / \mathrm{min}$ measured by hyperinsulinemic-euglycemic clamp, after 4 weeks of high-fat/high-saturated fat diet compared to a low-fat diet (glucose disposal rate $+0.12 \pm 0.11 \mathrm{mmol} / \mathrm{min}, P<0.01$ ) [41]. All factors discussed above together with chronic inflammatory state in obesity could explain the associations between LCHF diet, high saturated fat intake and high $\mathrm{HbA1c}$ that were robust in a subgroup of individuals with
BMI $\geq 25 \mathrm{~kg} / \mathrm{m}^{2}$. Consistently, recent meta-analyses have shown that low magnesium intake was associated with higher risk of T2DM by $17-22 \%[42,43]$.

This study has limitations that must be considered when evaluating its findings. This study could not refer to very low-carbohydrate ketogenic diets, as there are no data on ketosis status for this dataset. Notably, there is no standardized definition of LCHF diets, although $<26 \% \mathrm{E} \mathrm{CHO}$ has been proposed as a cut-off value [44]. Only $0.24 \%$ of the study sample $(n=8 / 3234)$ consumed carbohydrates below this threshold, a finding comparable to data from the UK Biobank (0.34\% of participants) [45]. As with all crosssectional studies, residual confounders and reverse causation could not be excluded; for example, the association between low-carbohydrate intake and T2DM prevalence could be explained by that those with diabetes might have changed their dietary behaviour by reducing carbohydrate intake. We, therefore, conducted analyses in a population mainly without diabetes, including in-depth sensitivity analyses and used a biomarker (HbA1c) as an outcome to minimize bias. The LCHF score is arbitrary. However, this score allows a practical approach to assess dietary pattern, reflecting the complementarity of food/nutrient intakes rather than focusing on single nutrients that are never consumed in isolation [46]. Finally, we could not distinguish between type 1 and type 2 diabetes, including those with insulin use, in the present study. However, the prevalence of type 1 diabetes is approximately $0.6 \%$ of UK population (about $10 \%$ of people with diabetes in the UK [26]); any individuals with type 1 diabetes in the sample could have little impact on our analyses, as shown through exclusion simulations in our sensitivity analyses.

A key strength of our study is its use of the UK nationally representative data for hypothesis testing on a topic of substantial scientific and public interest. Results could, therefore, be generalizable to the UK population and possibly to other countries, as dietary recommendations (to eat more whole grain, fruits and vegetables, and lower fat, saturated fat, sodium and sugar) are rather similar across many countries [47, 48]. Using prospective dietary records does not rely on memory so may provide more accurate estimates of actual intakes than food frequency questionnaires.

Regarding diabetes prevention, our cross-sectional results oppose the simplistic notion that lower carbohydrate contents in the diet per se could lower HbA1c concentration, particularly in people without diagnosed diabetes. Longterm, high-quality randomized controlled trials of LCHF diets on diabetes prevention are needed before such diets should be recommended.

Acknowledgements $\mathrm{CC}$ has received $\mathrm{PhD}$ scholarship from the Prince of Songkla University, Faculty of Medicine, Thailand. Data sharing: 
Data of the National Diet and Nutrition Survey are available upon application and approval from the UK Data Service (www.ukdat aservice.ac.uk), which can be accessed online: http://doi.org/10.5255/ UKDA-SN-6533-12

Author contributions $\mathrm{CC}$ developed research question, prepared the dataset, and conducted analyses with inputs from MEJL and EC. CC drafted the manuscript. All authors critically reviewed and revised the manuscript and have read and approved the final version.

Funding $\mathrm{CC}$ has received PhD scholarship from the Prince of Songkla University, Faculty of Medicine, Thailand.

\section{Compliance with ethical standards}

Conflict of interest MEJL has received departmental research support from Diabetes UK, Cambridge Weight Plan and Novo Nordisk and consultancy fees and support for meeting attendance from Novo Nordisk, Eli Lilly, Novartis, Counterweight Ltd and Eat Balanced. EC declares no conflict of interest.

Ethical approval All participants gave their consent being included in the National Diet and Nutrition Survey. The survey was granted by appropriate Local Research Ethics Committees and the data can be accessed online through the UK Data Service.

Open Access This article is distributed under the terms of the Creative Commons Attribution 4.0 International License (http://creativeco mmons.org/licenses/by/4.0/), which permits unrestricted use, distribution, and reproduction in any medium, provided you give appropriate credit to the original author(s) and the source, provide a link to the Creative Commons license, and indicate if changes were made.

\section{References}

1. International Diabetes Federation (2017) IDF diabetes atlas, 8th edn. https://diabetesatlas.org. Accessed 20 Nov 2018

2. Lean ME, Leslie WS, Barnes AC, Brosnahan N, Thom G, McCombie L, Peters C, Zhyzhneuskaya S, Al-Mrabeh A, Hollingsworth KG, Rodrigues AM, Rehackova L, Adamson AJ, Sniehotta FF, Mathers JC, Ross HM, McIlvenna Y, Stefanetti R, Trenell M, Welsh P, Kean S, Ford I, McConnachie A, Sattar N, Taylor R (2018) Primary care-led weight management for remission of type 2 diabetes (DiRECT): an open-label, clusterrandomised trial. Lancet 391(10120):541-551. https://doi. org/10.1016/S0140-6736(17)33102-1

3. Dunkley AJ, Bodicoat DH, Greaves CJ, Russell C, Yates T, Davies MJ, Khunti K (2014) Diabetes prevention in the real world: effectiveness of pragmatic lifestyle interventions for the prevention of type 2 diabetes and of the impact of adherence to guideline recommendations: a systematic review and meta-analysis. Diabetes Care 37(4):922-933. https://doi.org/10.2337/dc13-2195

4. Howard BV, Aragaki AK, Tinker LF, Allison M, Hingle MD, Johnson KC, Manson JE, Shadyab AH, Shikany JM, Snetselaar LG, Thomson CA, Zaslavsky O, Prentice RL (2018) A lowfat dietary pattern and diabetes: a secondary analysis from the women's health initiative dietary modification trial. Diabetes Care 41(4):680-687. https://doi.org/10.2337/dc17-0534

5. Knowler WC, Barrett-Connor E, Fowler SE, Hamman RF, Lachin JM, Walker EA, Nathan DM, Diabetes Prevention Program
Research G (2002) Reduction in the incidence of type 2 diabetes with lifestyle intervention or metformin. N Engl J Med 346(6):393-403. https://doi.org/10.1056/nejmoa012512

6. Tuomilehto J, Lindstrom J, Eriksson JG, Valle TT, Hamalainen H, Ilanne-Parikka P, Keinanen-Kiukaanniemi S, Laakso M, Louheranta A, Rastas M, Salminen V, Uusitupa M, Finnish Diabetes Prevention Study G (2001) Prevention of type 2 diabetes mellitus by changes in lifestyle among subjects with impaired glucose tolerance. N Engl J Med 344(18):1343-1350. https://doi.org/10.1056/ nejm200105033441801

7. Fernemark H, Jaredsson C, Bunjaku B, Rosenqvist U, Nystrom $\mathrm{FH}$, Guldbrand H (2013) A randomized cross-over trial of the postprandial effects of three different diets in patients with type 2 diabetes. PLoS One 8(11):e79324. https://doi.org/10.1371/journ al.pone. 0079324

8. Kang X, Wang C, Lifang L, Chen D, Yang Y, Liu G, Wen H, Chen L, He L, Li X, Tian H, Jia W, Ran X (2013) Effects of different proportion of carbohydrate in breakfast on postprandial glucose excursion in normal glucose tolerance and impaired glucose regulation subjects. Diabetes Technol Ther 15(7):569-574. https://doi. org/10.1089/dia.2012.0305

9. Dyson P, McArdle P, Mellor D, Guess N (2019) James Lind Alliance research priorities: what role do carbohydrates, fats and proteins have in the management of type 2 diabetes, and are there risks and benefits associated with particular approaches? Diabet Med 36(3):287-296. https://doi.org/10.1111/dme.13826

10. Churuangsuk C, Kherouf M, Combet E, Lean M (2018) Lowcarbohydrate diets for overweight and obesity: a systematic review of the systematic reviews. Obes Rev 19(12):1700-1718. https:// doi.org/10.1111/obr.12744

11. Hallberg SJ, McKenzie AL, Williams PT, Bhanpuri NH, Peters AL, Campbell WW, Hazbun TL, Volk BM, McCarter JP, Phinney SD, Volek JS (2018) Effectiveness and safety of a novel care model for the management of type 2 diabetes at 1 year: an openlabel, non-randomized, controlled study. Diabetes Ther 9(2):583612. https://doi.org/10.1007/s13300-018-0373-9

12. Korsmo-Haugen HK, Brurberg KG, Mann J, Aas AM (2019) Carbohydrate quantity in the dietary management of type 2 diabetes: a systematic review and meta-analysis. Diabetes Obes Metab 21(1):15-27. https://doi.org/10.1111/dom.13499

13. van Zuuren EJ, Fedorowicz Z, Kuijpers T, Pijl H (2018) Effects of low-carbohydrate- compared with low-fat-diet interventions on metabolic control in people with type 2 diabetes: a systematic review including GRADE assessments. Am J Clin Nutr 108(2):300-331. https://doi.org/10.1093/ajcn/nqy096

14. Churuangsuk C, Griffiths D, Lean MEJ, Combet E (2019) Impacts of carbohydrate-restricted diets on micronutrient intakes and status: a systematic review. Obes Rev. https://doi.org/10.1111/ obr. 12857

15. de Koning L, Fung TT, Liao X, Chiuve SE, Rimm EB, Willett WC, Spiegelman D, Hu FB (2011) Low-carbohydrate diet scores and risk of type 2 diabetes in men. Am J Clin Nutr 93(4):844-850. https://doi.org/10.3945/ajcn.110.004333

16. Halton TL, Liu S, Manson JE, Hu FB (2008) Low-carbohydratediet score and risk of type 2 diabetes in women. Am J Clin Nutr 87(2):339-346. https://doi.org/10.1093/ajcn/87.2.339

17. Nanri A, Mizoue T, Kurotani K, Goto A, Oba S, Noda M, Sawada N, Tsugane S, Japan Public Health Center-Based Prospective Study G (2015) Low-carbohydrate diet and type 2 diabetes risk in Japanese men and women: the Japan Public Health CenterBased Prospective Study. PLoS One 10(2):e0118377. https://doi. org/10.1371/journal.pone.0118377

18. Guess ND (2018) dietary interventions for the prevention of type 2 diabetes in high-risk groups: current state of evidence and future research needs. Nutrients. https://doi.org/10.3390/nu10091245 
19. MRC Elsie Widdowson Laboratory, NatCen Social Research (2018) National Diet and Nutrition Survey Years 1-8, 2008/092015/16, 11th edn. UK Data Service. https://doi.org/10.5255/ ukda-sn-6533-11. Accessed 6 June 2018

20. Seidelmann SB, Claggett B, Cheng S, Henglin M, Shah A, Steffen LM, Folsom AR, Rimm EB, Willett WC, Solomon SD (2018) Dietary carbohydrate intake and mortality: a prospective cohort study and meta-analysis. Lancet Public Health 3(9):e419-e428. https://doi.org/10.1016/S2468-2667(18)30135-X

21. National Diet and Nutrition Survey Years 1 to 9 of the Rolling Programme (2008/2009-2016/2017): Time trend and income analyses (2019) https://www.gov.uk/government/statistics/ndnstime-trend-and-income-analyses-for-years-1-to-9. Accessed 25 June 2019

22. Sjogren P, Becker W, Warensjo E, Olsson E, Byberg L, Gustafsson IB, Karlstrom B, Cederholm T (2010) Mediterranean and carbohydrate-restricted diets and mortality among elderly men: a cohort study in Sweden. Am J Clin Nutr 92(4):967-974. https:// doi.org/10.3945/ajen.2010.29345

23. Eriksen R, Gibson R, Lamb K, McMeel Y, Vergnaud AC, Spear J, Aresu M, Chan Q, Elliott P, Frost G (2018) Nutrient profiling and adherence to components of the UK national dietary guidelines association with metabolic risk factors for CVD and diabetes: airwave health monitoring study. Br J Nutr 119(6):695-705. https ://doi.org/10.1017/S0007114518000016

24. Edelman D, Olsen MK, Dudley TK, Harris AC, Oddone EZ (2004) Utility of hemoglobin A1c in predicting diabetes risk. J Gen Intern Med 19(12):1175-1180. https://doi.org/10.111 1/j.1525-1497.2004.40178.x

25. Pfister R, Sharp SJ, Luben R, Khaw KT, Wareham NJ (2011) No evidence of an increased mortality risk associated with low levels of glycated haemoglobin in a non-diabetic UK population. Diabetologia 54(8):2025-2032. https://doi.org/10.1007/s0012 5-011-2162-0

26. National Diabetes Audit Report 1 Care Processes and Treatment Targets 2017-18 (2018) NHS sigital. https://digital.nhs.uk/dataand-information/publications/statistical/national-diabetes-audit /report-1-care-processes-and-treatment-targets-2017-18-short -report. Accessed 11 Feb 2019

27. Bao W, Li S, Chavarro JE, Tobias DK, Zhu Y, Hu FB, Zhang C (2016) Low carbohydrate-diet scores and long-term risk of type 2 diabetes among women with a history of gestational diabetes mellitus: a prospective cohort study. Diabetes Care 39(1):43-49. https://doi.org/10.2337/dc15-1642

28. Namazi N, Larijani B, Azadbakht L (2017) Low-carbohydrate-diet score and its association with the risk of diabetes: a systematic review and meta-analysis of cohort studies. Horm Metab Res 49(8):565-571. https://doi.org/10.1055/s-0043-112347

29. Cooper AJ, Forouhi NG, Ye Z, Buijsse B, Arriola L, Balkau B, Barricarte A, Beulens JW, Boeing H, Buchner FL, Dahm CC, de Lauzon-Guillain B, Fagherazzi G, Franks PW, Gonzalez C, Grioni S, Kaaks R, Key TJ, Masala G, Navarro C, Nilsson P, Overvad K, Panico S, Ramon Quiros J, Rolandsson O, Roswall N, Sacerdote C, Sanchez MJ, Slimani N, Sluijs I, Spijkerman AM, Teucher B, Tjonneland A, Tumino R, Sharp SJ, Langenberg C, Feskens EJ, Riboli E, Wareham NJ, InterAct C (2012) Fruit and vegetable intake and type 2 diabetes: EPIC-InterAct prospective study and meta-analysis. Eur J Clin Nutr 66(10):1082-1092. https://doi. org/10.1038/ejen.2012.85

30. Fung TT, Hu FB, Pereira MA, Liu S, Stampfer MJ, Colditz GA, Willett WC (2002) Whole-grain intake and the risk of type 2 diabetes: a prospective study in men. Am J Clin Nutr 76(3):535-540. https://doi.org/10.1093/ajcn/76.3.535

31. Ley SH, Pan A, Li Y, Manson JE, Willett WC, Sun Q, Hu FB (2016) Changes in overall diet quality and subsequent type 2 diabetes risk: three U.S. prospective cohorts. Diabetes Care 39(11):2011-2018. https://doi.org/10.2337/dc16-0574

32. Schwingshack1 L, Bogensberger B, Hoffmann G (2018) Diet quality as assessed by the healthy eating index, alternate healthy eating index, dietary approaches to stop hypertension score, and health outcomes: an updated systematic review and meta-analysis of cohort studies. J Acad Nutr Diet 118(1):74-100. https://doi. org/10.1016/j.jand.2017.08.024

33. Anderson EJ, Lustig ME, Boyle KE, Woodlief TL, Kane DA, Lin CT, Price JW 3rd, Kang L, Rabinovitch PS, Szeto HH, Houmard JA, Cortright RN, Wasserman DH, Neufer PD (2009) Mitochondrial $\mathrm{H} 2 \mathrm{O} 2$ emission and cellular redox state link excess fat intake to insulin resistance in both rodents and humans. J Clin Invest 119(3):573-581. https://doi.org/10.1172/JCI37048

34. Budai Z, Balogh L, Sarang Z (2019) Short-term high-fat meal intake alters the expression of circadian clock-, inflammation-, and oxidative stress-related genes in human skeletal muscle. Int J Food Sci Nutr 70(6):749-758. https://doi.org/10.1080/09637 486.2018.1557607

35. Cocate PG, Natali AJ, Oliveira A, Longo GZ, Alfenas Rde C, Peluzio Mdo C, Santos EC, Buthers JM, Oliveira LL, Hermsdorff HH (2014) Fruit and vegetable intake and related nutrients are associated with oxidative stress markers in middleaged men. Nutrition 30(6):660-665. https://doi.org/10.1016/j. nut.2013.10.015

36. Matsuzawa-Nagata N, Takamura T, Ando H, Nakamura S, Kurita S, Misu H, Ota T, Yokoyama M, Honda M, Miyamoto K, Kaneko S (2008) Increased oxidative stress precedes the onset of high-fat diet-induced insulin resistance and obesity. Metabolism 57(8):1071-1077. https://doi.org/10.1016/j.metabol.2008.03.010

37. Prior RL (2003) Fruits and vegetables in the prevention of cellular oxidative damage. Am J Clin Nutr 78(3 Suppl):570S-578S. https ://doi.org/10.1093/ajen/78.3.570S

38. Vlassopoulos A, Lean ME, Combet E (2013) Role of oxidative stress in physiological albumin glycation: a neglected interaction. Free Radic Biol Med 60:318-324. https://doi.org/10.1016/j.freer adbiomed.2013.03.010

39. Barazzoni R, Zanetti M, Gortan Cappellari G, Semolic A, Boschelle M, Codarin E, Pirulli A, Cattin L, Guarnieri G (2012) Fatty acids acutely enhance insulin-induced oxidative stress and cause insulin resistance by increasing mitochondrial reactive oxygen species (ROS) generation and nuclear factor-kappaB inhibitor (IkappaB)-nuclear factor-kappaB (NFkappaB) activation in rat muscle, in the absence of mitochondrial dysfunction. Diabetologia 55(3):773-782. https://doi.org/10.1007/s00125-011-2396-X

40. Gommers LM, Hoenderop JG, Bindels RJ, de Baaij JH (2016) Hypomagnesemia in type 2 diabetes: a vicious circle? Diabetes 65(1):3-13. https://doi.org/10.2337/db15-1028

41. von Frankenberg AD, Marina A, Song X, Callahan HS, Kratz M, Utzschneider KM (2017) A high-fat, high-saturated fat diet decreases insulin sensitivity without changing intra-abdominal fat in weight-stable overweight and obese adults. Eur J Nutr 56(1):431-443. https://doi.org/10.1007/s00394-015-1108-6

42. Dong JY, Xun P, He K, Qin LQ (2011) Magnesium intake and risk of type 2 diabetes: meta-analysis of prospective cohort studies. Diabetes Care 34(9):2116-2122. https://doi.org/10.2337/ dc11-0518

43. Fang X, Han H, Li M, Liang C, Fan Z, Aaseth J, He J, Montgomery S, Cao Y (2016) Dose-response relationship between dietary magnesium intake and risk of type 2 diabetes mellitus: a systematic review and meta-regression analysis of prospective cohort studies. Nutrients. https://doi.org/10.3390/nu8110739

44. Feinman RD, Pogozelski WK, Astrup A, Bernstein RK, Fine EJ, Westman EC, Accurso A, Frassetto L, Gower BA, McFarlane SI, Nielsen JV, Krarup T, Saslow L, Roth KS, Vernon MC, Volek JS, Wilshire GB, Dahlqvist A, Sundberg R, Childers A, Morrison 
K, Manninen AH, Dashti HM, Wood RJ, Wortman J, Worm N (2015) Dietary carbohydrate restriction as the first approach in diabetes management: critical review and evidence base. Nutrition 31(1):1-13. https://doi.org/10.1016/j.nut.2014.06.011

45. Shafique M, Russell S, Murdoch S, Bell JD, Guess N (2018) Dietary intake in people consuming a low-carbohydrate diet in the UK Biobank. J Hum Nutr Diet 31(2):228-238. https://doi. org/10.1111/jhn. 12527

46. Jacobs DR Jr, Steffen LM (2003) Nutrients, foods, and dietary patterns as exposures in research: a framework for food synergy.
Am J Clin Nutr 78(3 Suppl):508S-513S. https://doi.org/10.1093/ ajen/78.3.508S

47. U.S. Department of Health and Human Services and U.S. Department of Agriculture (2015) 2015-2020 Dietary guidelines for Americans, 8th edn. https://health.gov/dietaryguidelines/2015/ guidelines/. Accessed 27 Nov 2018

48. Levy L, Tedstone A (2017) UK dietary policy for the prevention of cardiovascular disease. Multidisciplinary Digital Publishing Institute, London 